\title{
Curing of Highly Loaded Ceramic Suspensions in Acrylates
}

\author{
Tien-Min Gabriel Chu* and John W. Halloran*
}

Department of Materials Science and Engineering, University of Michigan, Ann Arbor, Michigan 48105

\begin{abstract}
The objective of this study is to use differential scanning calorimetry (DSC) to characterize the curing kinetics of $\mathrm{Al}_{2} \mathrm{O}_{3}$ and hydroxyapatite suspensions in acrylates. The heat evolution of the acrylate premix and ceramic suspensions in dynamic and isothermal curing was measured. The calculated activation energies for the acrylate premix and the two ceramic suspensions were 133,74 , and $78 \mathrm{~kJ} / \mathrm{mol}$, indicating a catalytic effect of the ceramic fillers. The curing behavior of the two ceramic suspensions modeled with the autocatalytic polymerization model with satisfactory results.
\end{abstract}

\section{Introduction}

Cuspensions of ceramic powder in acrylate monomers have been Sformulated to make complex-shaped ceramic objects. Venkataswamy et al. ${ }^{1}$ dispersed $\mathrm{SiC}, \mathrm{Al}_{2} \mathrm{O}_{3}$, and $\mathrm{Y}_{2} \mathrm{O}_{3}$ in n-butyl methacrylate, methacrylic acid, and diethylene glycol dimethacrylate. The slip was injected into molds and cured by heat. The acrylate binder in the cured suspensions was pyrolyzed, and the ceramic green bodies were sintered into near-net-shape ceramics. Similar suspensions of $\mathrm{Al}_{2} \mathrm{O}_{3}$ powders in trimethylolpropane triacrylate and hexanediol diacrylates, ${ }^{2}$ and $\mathrm{Al}_{2} \mathrm{O}_{3}$ powder in acrylamide $(\mathrm{AM})$ and $\mathrm{N}, \mathrm{N}^{\prime}$-methylenebisacrylamide $(\mathrm{MBAM})^{3}$ also had been reported. The term "gelcasting" was later applied to such a ceramic processing method. ${ }^{3,4}$

The curing kinetics of these types of ceramic suspensions is important in the processing of these suspensions. Young et al. ${ }^{3}$ measured the temperature change during the exothermic polymerization reaction in the premix. The activation energy of the resin premix was calculated from the idle time before temperature increase during curing. The effect of catalyst on the activation energy of the premix was demonstrated. The effect of the ceramic fillers on activation energy and curing kinetics was not mentioned, however, by Young. Inorganic fillers are known to affect the curing kinetics of thermal-setting polymers. ${ }^{5}$ In this paper, a 50 vol\% $\mathrm{Al}_{2} \mathrm{O}_{3}$ suspension and a 40 vol\% hydroxyapatite (HA) suspension with potential applications for the above-mentioned casting and forming process were used. The curing behavior of the suspensions was investigated using differential scanning calorimetry (DSC). The activation energy, rate of polymerization, degree of polymerization, and effect of ceramic fillers were studied. Modeling of the curing kinetics of these suspensions was further explored with an autocatalytic polymerization model.

\section{Experimental Methods}

An $\mathrm{Al}_{2} \mathrm{O}_{3}$ powder (A-16, Alcoa Industrial Chemicals, Pittsburgh, PA) with an average size $\left(D_{50}\right)$ of $0.4 \mu \mathrm{m}$ was used in this study. Under SEM (Model S-800, Hitachi, Tokyo, Japan), the particles were spherical in shape. The density of the powder was

P. W. Brown—contributing editor
$3.92 \mathrm{~g} / \mathrm{cm}^{3}$, and the specific surface area was $9.5 \mathrm{~m}^{2} / \mathrm{g}$ (manufacturer's data). The HA powder used was needle-shaped, $60 \mathrm{~nm} \times$ $600 \mathrm{~nm}$ long. The density of the powder was $3.14 \mathrm{~g} / \mathrm{cm}^{3}$, as measured with a helium pycnometer (Model AccuPyc 1330, Micromeritics Instrument Corp., Norcross, GA). The BET specific surface area of this powder was reported by Ruys et al. ${ }^{6}$ to be 17 $\mathrm{m}^{2} / \mathrm{g}$.

The liquid medium was a 1:1 mixture of propoxylated neopentoglycol diacrylate (PNPGDA) and isobornyl acrylate (IBA). The $\mathrm{Al}_{2} \mathrm{O}_{3}$ powder was dispersed with a commercial product based on quaternary ammonium acetate (Emcol CC-55, Witco Corp., Houston, TX). The HA powder was dispersed with quaternary ammonium acetate and aromatic phosphate ester (Emphos CS-1361, Witco Corp., Houston, TX). The formulation processes of these two suspensions were reported elsewhere. ${ }^{7,8}$ The 50 vol\% $\mathrm{Al}_{2} \mathrm{O}_{3}$ suspension and $40 \mathrm{vol} \%$ HA suspension were prepared by incrementally adding the ceramic powder to the PNPGDA/IBA premix along with a dispersant, followed by vigorous mixing. A $0.15 \%$ benzoyl peroxide (BPO) to the weight of the monomers was added to both suspensions as a thermal initiator. The BPO decomposed on heating, releasing free radicals, which initiated the polymerization reaction of the PNPGDA/IBA monomers. The curing kinetics of the ceramic suspensions was investigated with DSC (Model DSC-7, Perkin-Elmer, Norwalk, CT). BPO was added to both suspensions just before testing. The $\mathrm{Al}_{2} \mathrm{O}_{3}$ suspensions were isothermally cured at $60^{\circ}, 70^{\circ}, 80^{\circ}$, and $90^{\circ} \mathrm{C}$, and the $\mathrm{HA}$ suspensions were isothermally cured at $70^{\circ}, 80^{\circ}$, and $90^{\circ} \mathrm{C}$ on the DSC. The neat PNPGDA/IBA without any ceramic filler was also cured isothermally at $90^{\circ}, 95^{\circ}$, and $100^{\circ} \mathrm{C}$. The rate of heat evolution from the polymerization reaction was recorded.

\section{Results and Discussion}

\section{(1) Percent Conversion and Rate of Polymerization}

For the two ceramic suspensions, a single exothermic peak was found in all the isothermal DSC traces. A typical DSC trace, such as $\mathrm{Al}_{2} \mathrm{O}_{3} / \mathrm{PNPGDA} / \mathrm{IBA}$ cured at $60^{\circ} \mathrm{C}$, is shown in Fig. 1 . All the cured samples were scanned again from $30^{\circ}$ to $200^{\circ} \mathrm{C}$ at $10^{\circ} \mathrm{C} / \mathrm{min}$, and no more heat generation was detected, indicating curing was complete. The relative percent conversion $(\alpha)$ in the cured suspensions was calculated by taking the cumulative heat evolved at given time $(Q)$ and dividing it by the total heat of evolution $\left(Q_{\mathrm{T}}\right)$.

$$
\alpha=\frac{Q}{Q_{\mathrm{T}}}
$$

Figure 2 and Fig. 3 show the relative percent conversion versus time for $\mathrm{Al}_{2} \mathrm{O}_{3}$ and $\mathrm{HA}$ suspensions. For $\mathrm{Al}_{2} \mathrm{O}_{3}$ suspensions, the reaction at $60^{\circ} \mathrm{C}$ started in $\sim 22 \mathrm{~min}$ and reached $100 \%$ relative conversion in $\sim 80 \mathrm{~min}$. The initiation time decreased to $8 \mathrm{~min}, 1.5$ min, and $10 \mathrm{~s}$ as curing temperatures increased to $70^{\circ}, 80^{\circ}$, and $90^{\circ} \mathrm{C}$, respectively. In HA suspension, the reaction at $70^{\circ} \mathrm{C}$ started in $\sim 8 \mathrm{~min}$ and reached $100 \%$ in $\sim 60 \mathrm{~min}$. The initiation time decreased to $3 \mathrm{~min}$ and $1 \mathrm{~min}$ as curing temperatures increased to $80^{\circ}$ and $90^{\circ} \mathrm{C}$, respectively.

The rate of polymerization $\left(R_{\mathrm{p}}\right)$ of the suspensions was calculated by taking the time derivative of percent conversion as:

$$
R_{\mathrm{p}}=\frac{\mathrm{d} \alpha}{\mathrm{d} t}
$$




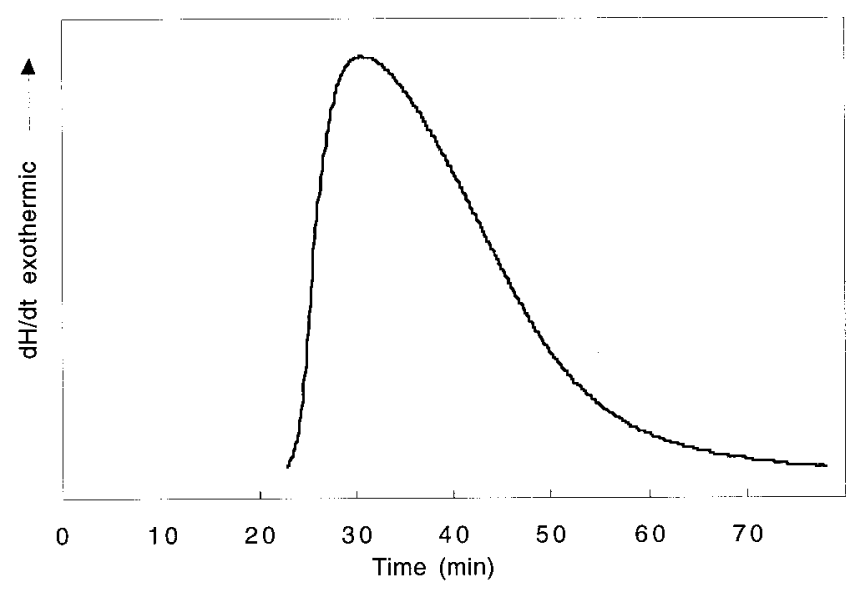

Fig. 1. DSC trace of $\mathrm{Al}_{2} \mathrm{O}_{3} / \mathrm{PNPGDA} / \mathrm{IBA}$ cured at $60^{\circ} \mathrm{C}$.

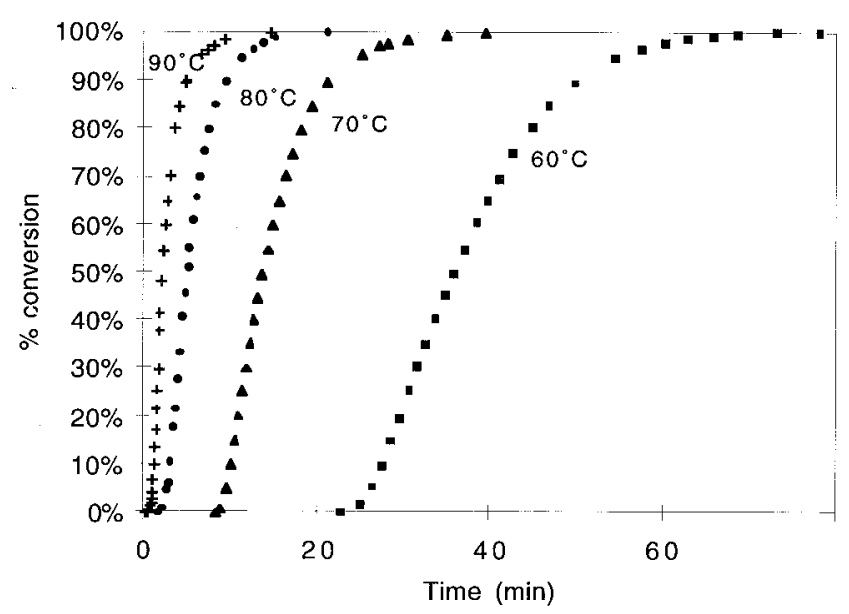

Fig. 2. Relative percent conversion of $\mathrm{Al}_{2} \mathrm{O}_{3} / \mathrm{PNPGDA} / \mathrm{IBA}$ vs time.

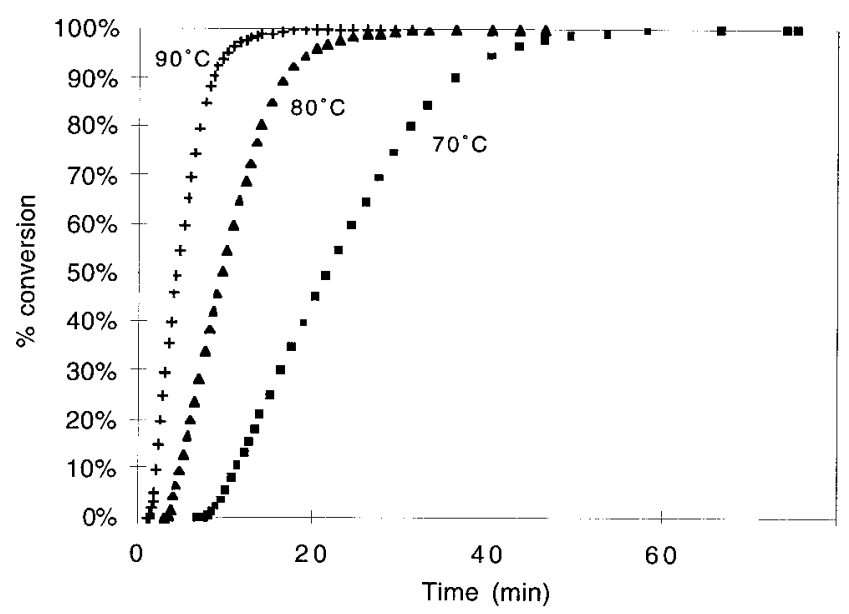

Fig. 3. Relative percent conversion of HA/PNPGDA/IBA vs time.

The rates of polymerization versus time for both $\mathrm{Al}_{2} \mathrm{O}_{3}$ suspension and HA suspension are shown in Fig. 4 and Fig. 5. The maximum in the rate of polymerization versus time plot indicates the polymerization reaction is autocatalytic, ${ }^{5}$ as one would expect from a radical chain polymerization. ${ }^{9}$ The peak polymerization rate for $\mathrm{Al}_{2} \mathrm{O}_{3}$ slip is $0.082 \% / \mathrm{s}$ at $60^{\circ} \mathrm{C}$ and $0.76 \% / \mathrm{s}$ at $90^{\circ} \mathrm{C}$. The peak polymerization rate for $\mathrm{HA}$ slip is $0.068 \% / \mathrm{s}$ at $70^{\circ} \mathrm{C}$ and $0.31 \% / \mathrm{s}$ at $90^{\circ} \mathrm{C}$.

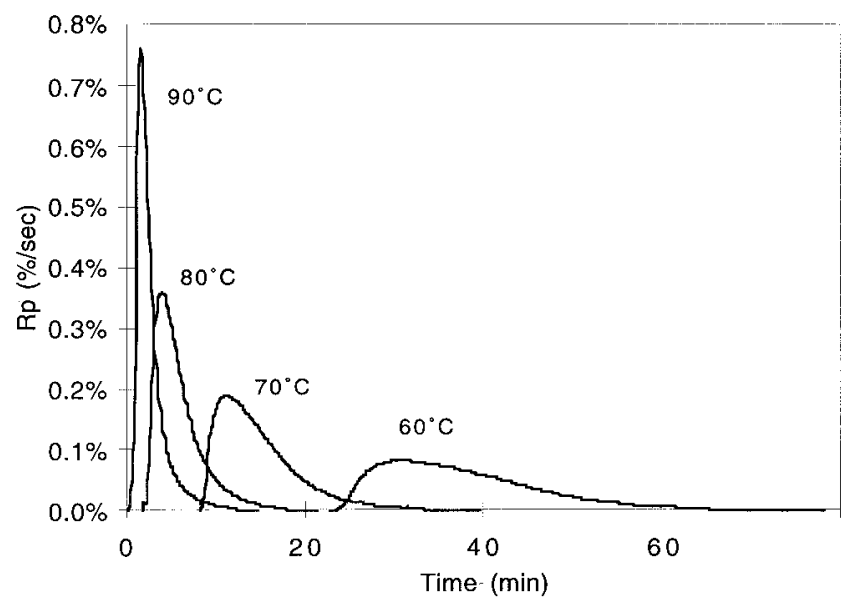

Fig. 4. Relative rate of polymerization of $\mathrm{Al}_{2} \mathrm{O}_{3} / \mathrm{PNPGDA} / \mathrm{IBA}$ vs time.

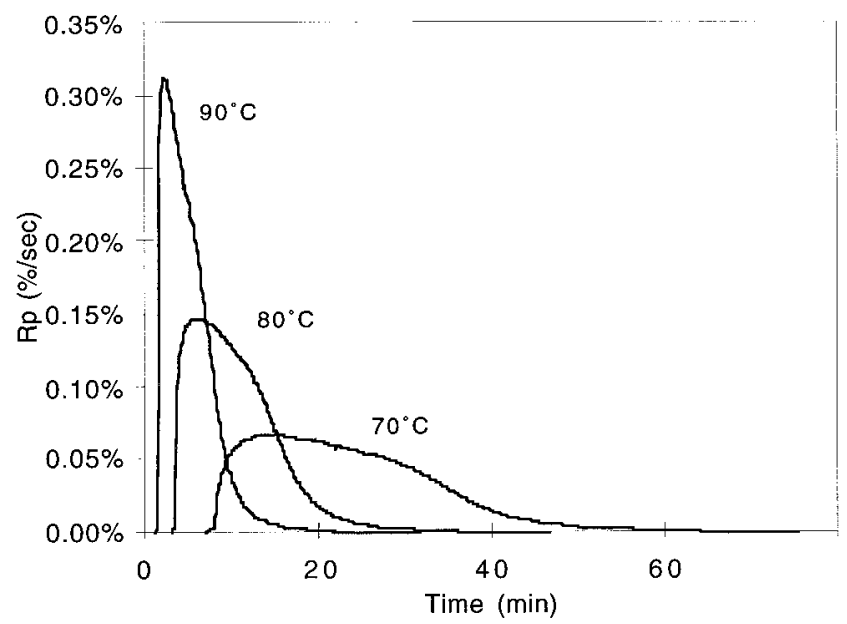

Fig. 5. Relative rate of polymerization of HA/PNPGDA/IBA vs time.

\section{(2) Activation Energy of Ceramic Suspension}

The peak polymerization rate has been used to calculate the activation energy of $\mathrm{a} \mathrm{CaCO}_{3}$-filled unsaturated polyester resin. ${ }^{10}$ The same method was used in this study. The peak polymerization rates of $\mathrm{Al}_{2} \mathrm{O}_{3}$ slip and $\mathrm{HA}$ slip at various curing temperatures are listed in Table I. When the peak polymerization rates were plotted against the inverse of the curing temperatures, an Arrhenius relation was found in both suspensions, as shown in Fig. 6. The activation energy calculated from the slope of each data pair in the curve was $74 \pm 5 \mathrm{~kJ} / \mathrm{mol}$ for $\mathrm{Al}_{2} \mathrm{O}_{3}$ suspension and $78 \pm 1 \mathrm{~kJ} / \mathrm{mol}$ for HA suspension.

Note that, although the activation energy of $\mathrm{Al}_{2} \mathrm{O}_{3}$ and $\mathrm{HA}$ suspensions are essentially the same, the reaction rate of $\mathrm{Al}_{2} \mathrm{O}_{3}$ suspension is always higher than the reaction rate of HA suspension. A possible reason is discussed. The basic polymerization rate equation has the following form: ${ }^{5}$

$$
\frac{\mathrm{d} \alpha}{\mathrm{d} t}=k f(\alpha)
$$

Table I. Peak Polymerization Rate for $\mathrm{Al}_{2} \mathrm{O}_{3}$ and $\mathrm{HA}$ Suspensions

\begin{tabular}{lllll}
\hline & \multicolumn{4}{c}{ Peak polymerization rate (\%/s) } \\
\cline { 2 - 5 } \multicolumn{1}{c}{ Suspension } & $60^{\circ} \mathrm{C}$ & $70^{\circ} \mathrm{C}$ & $80^{\circ} \mathrm{C}$ & $90^{\circ} \mathrm{C}$ \\
\hline $\mathrm{Al}_{2} \mathrm{O}_{3} /$ PNPGDA/IBA & 0.082 & 0.19 & 0.36 & 0.76 \\
$\mathrm{HA} / \mathrm{PNPGDA} / \mathrm{IBA}$ & & 0.068 & 0.15 & 0.31 \\
\hline
\end{tabular}




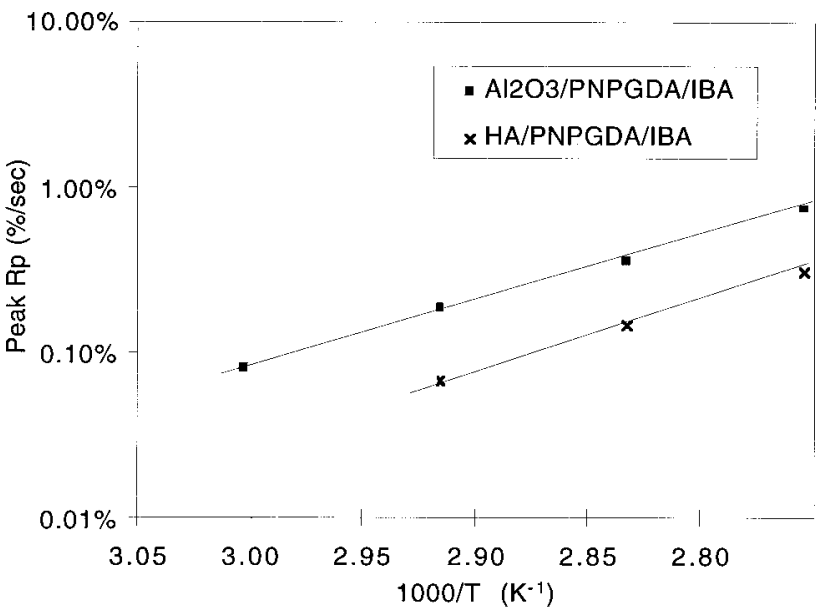

Fig. 6. Peak polymerization rate vs inverse of curing temperature. Activation energy of $\mathrm{Al}_{2} \mathrm{O}_{3}$ and $\mathrm{HA}$ suspensions was calculated from slope of curves to be 74 and $78 \mathrm{~kJ} / \mathrm{mol}$.

which states that the polymerization rate is related to some function of the concentration of reactants $(f(\alpha))$ through a rate constant $(k)$. The temperature effect on $k$ can be expressed as:

$$
k=A \exp (-E / R T)
$$

where $A$ is the preexponential factor, $E$ the activation energy, $R$ the gas constant, and $T$ the reaction temperature in degrees Kelvin. The $E$ describes the overall chemical threshold energy required for the initiation, propagation, and termination in the polymerization reaction. ${ }^{9}$ The preexponent $A$ describes other physical factors related to the reaction condition. As shown in Eqs. (3) and (4), two reactions with similar $E$ can be very different in the overall reaction rate $(\mathrm{d} \alpha / \mathrm{d} t)$ because of the difference in $A$ and $f(\alpha)$. The complexity of our reaction system requires more extensive study to draw any further conclusions.

\section{(3) Activation Energy of Neat Acrylates}

The activation energy of neat PNPGDA/IBA without any ceramic filler was also studied. In the isothermal curing of PNPGDA/IBA, two exothermic peaks were found in all DSC traces. A typical scan is shown in Fig. 7. The total heat of evolution of neat PNPGDA/IBA was $374 \mathrm{~J} / \mathrm{g}$ monomer, and the average heat of reaction per mole monomer mix was calculated to be $67 \mathrm{~kJ} / \mathrm{mol}$ $\mathrm{C}=\mathrm{C}$. This was in agreement with the typical heat of reaction of $67-84 \mathrm{~kJ} / \mathrm{mol}$ for acrylate monomers. ${ }^{11}$

For a reaction with complicated exotherms, a dynamic DSC method instead of isothermal method has been recommended to

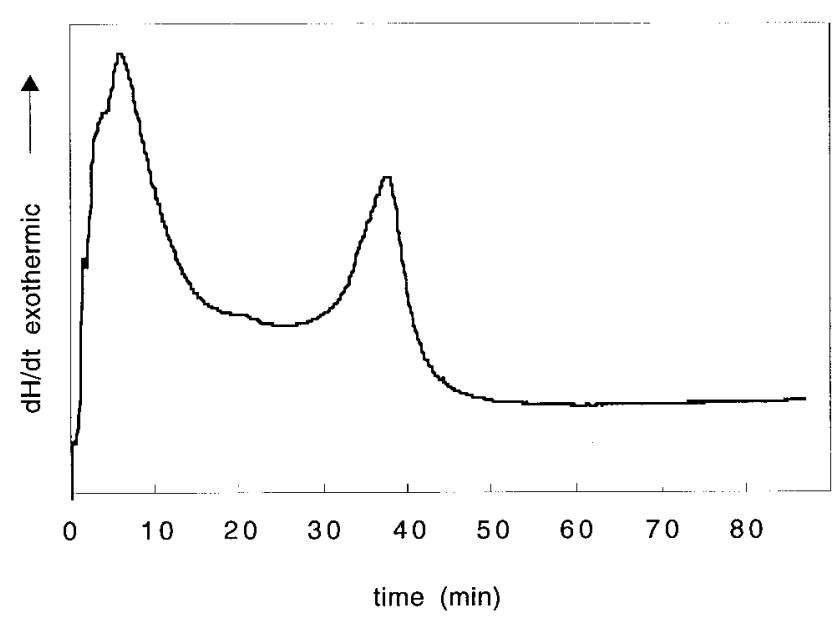

Fig. 7. Exotherm of PNPGDA/IBA premix cured at $95^{\circ} \mathrm{C}$.

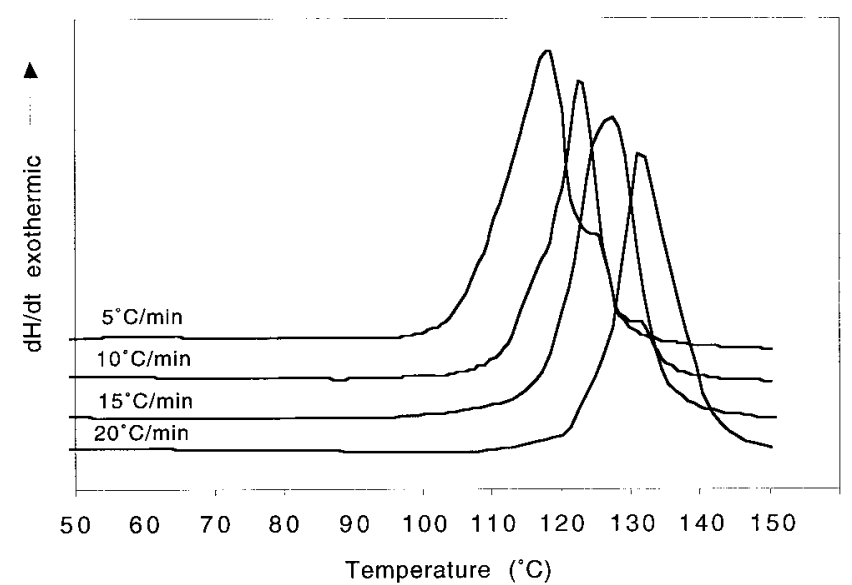

Fig. 8. Traces of dynamic DSC scan of PNPGDA/IBA premix cured at heating rates of $5^{\circ}, 10^{\circ}, 15^{\circ}$, and $20^{\circ} \mathrm{C} / \mathrm{min}$.

derive the overall activation energy. ${ }^{5}$ By changing the heating rates in curing, the temperature at which the peak exotherm occurs changes. From the heating rate and the peak exotherm temperature, the $E$ can be calculated as follows:

$$
E=\frac{-R}{1.052} \frac{\Delta(\ln \beta)}{\Delta\left(1 / T_{\mathrm{p}}\right)}
$$

where $R$ is the gas constant, $\beta$ the heating rate, and $T_{\mathrm{p}}$ the temperature when the peak exotherm occurs. With the above equation, Duswalt ${ }^{12}$ found the calculated activation energy was within a precision of $\pm 3 \%$. This dynamic scan method was used. The PNPGDA/IBA premix with $0.15 \% \mathrm{BPO}$ was heated with a heating rate of $5^{\circ}, 10^{\circ}, 15^{\circ}$, and $20^{\circ} \mathrm{C} / \mathrm{min}$ from $30^{\circ}$ to $150^{\circ} \mathrm{C}$, and the peak exotherm temperatures were recorded. The DSC traces at various heating rates are shown in Fig. 8. The natural logarithm of the heating rate was plotted against $1 / T_{\mathrm{p}}$ (Fig. 9), and the slope of the curve was obtained. The activation energy of the PNPGDA/ IBA premix was calculated from the slope to be $133 \mathrm{~kJ} / \mathrm{mol}$.

The activation energy of a polymerization reaction initiated by thermal initiator decomposition falls into a small range between 80 and $90 \mathrm{~kJ} / \mathrm{mol}^{9}{ }^{9}$ The calculated activation energy of our PNPGDA/ IBA is significantly higher than this number. A possible reason is the inhibitors commonly added in the monomer to prevent premature reaction or gelation and to increase shelf life. ${ }^{13}$ For instance, our PNPGDA is inhibited with $374 \mathrm{ppm}$ of hydroquinone, and IBA with 159 ppm MEHQ (manufacturer's data). The activation energies of acrylates in the literature are usually studied using

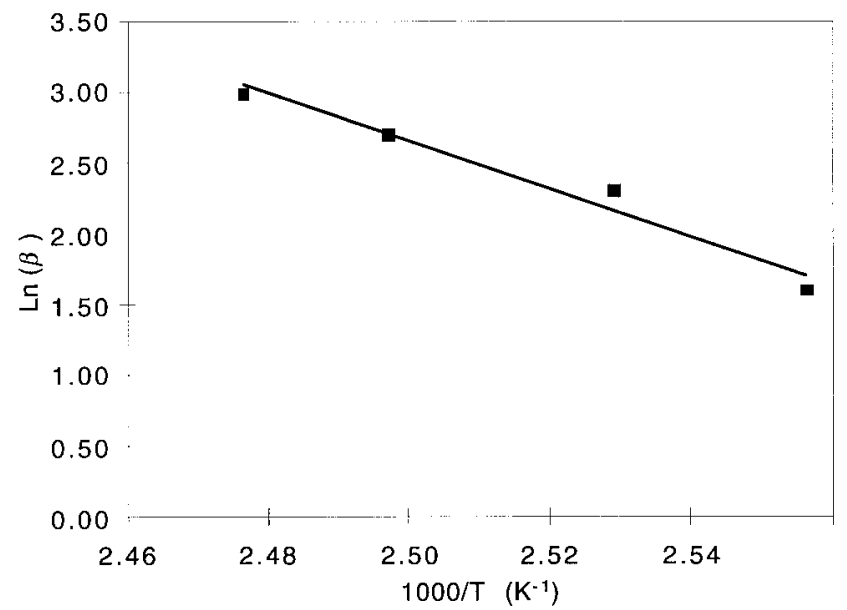

Fig. 9. Logarithm of heating rate vs inverse of peak exotherm temperature. Activation energy of PNPGDA/IBA premix was calculated from slope of curve to be $133 \mathrm{~kJ} / \mathrm{mol}$. 


Table II. Best Fit $k, m$, and $n$ Parameters for $\mathrm{Al}_{2} \mathrm{O}_{3} /$ PNPGDA/IBA and HA/PNPGDA/IBA Cured at Various Temperatures

\begin{tabular}{lccc}
\hline Temperature $\left({ }^{\circ} \mathrm{C}\right)$ & $k$ & $m$ & $n$ \\
\hline \multicolumn{4}{c}{$\mathrm{Al}_{2} \mathrm{O}_{3} / \mathrm{PNPGDA} / \mathrm{IBA}$} \\
60 & 0.0015 & 0.270 & 0.780 \\
70 & 0.0039 & 0.308 & 1.000 \\
80 & 0.0100 & 0.470 & 1.270 \\
90 & 0.0250 & 0.500 & 1.500 \\
70 & $\mathrm{HA} / \mathrm{PNPGDA} / \mathrm{IBA}$ \\
80 & 0.0011 & 0.200 & 0.600 \\
90 & 0.0023 & 0.189 & 0.650 \\
& 0.0045 & 0.130 & 0.700 \\
\hline
\end{tabular}

monomers free of inhibitors after multistep purification processes. ${ }^{14,15}$ Because we tested the monomers in the as-received condition without any purification, a higher apparent activation energy than the theoretical value is expected. Testing the monomers in the as-received condition is appropriate, because this best simulates the way the ceramic suspension is prepared under actual processing conditions.

From the above results, we found the ceramic fillers had significant effects on the curing of the acrylate monomers. First, the exotherms changed from two peaks in the neat PNPGDA/IBA to a single peak in the ceramic-filled systems. Also, the apparent activation energy of the acrylates was reduced from $133 \mathrm{~kJ} / \mathrm{mol}$ to 74 and $78 \mathrm{~kJ} / \mathrm{mol}$ after the ceramic powders were added. The effect of fillers on the polymerization kinetics of the polymers could be a function of the type and amount of fillers present. Lee et al. ${ }^{16}$ found the exotherm in the bisphenol A/4,4'-methylene dianiline/ malononitrile system changed from a single peak to double peaks after zeolite powders were added. The change in the exotherm suggested a change in the curing mechanism in the premix. Dutta and Ryan $^{17}$ detected no change in the activation energy after a commercial epoxy resin was filled with $8 \mathrm{wt} \%$ carbon black. Lem and $\mathrm{Han}^{10}$ found the activation energy of a commercial unsaturated polyester reduced significantly from 83 to $37.5 \mathrm{~kJ} / \mathrm{mol}$ when $50 \mathrm{wt} \% \mathrm{CaCO}_{3}$ was added. The reduction in the apparent activation energy observed in our filled system indicated the ceramic fillers had a catalytic effect on the polymerization reaction. ${ }^{5}$

\section{(4) Kinetic Modeling of Ceramic Suspension}

Modeling of the curing kinetics of our suspensions was then explored. The kinetic equation of an autocatalytic polymerization was proposed by $\mathrm{Kamal}^{18}$ to be:

$$
R_{\mathrm{p}}=\frac{\mathrm{d} \alpha}{\mathrm{d} t}=k \alpha^{m}(1-\alpha)^{n}
$$

where $k$ is the rate constant, and $m$ and $n$ the reaction orders. Kamal and co-workers ${ }^{18,19}$ found temperature-independent $m$ and $n$ values when the model was fitted to the curing kinetics between pure diglycidyl ether of bisphenol $\mathrm{A}$ and $\mathrm{m}$-phenylenediamine. When Dutta and Ryan ${ }^{17}$ tried to model the curing kinetics of an 8 wt $\%$ carbon-black-filled epoxy cured between $70^{\circ}$ and $170^{\circ} \mathrm{C}$, they were not able to come out with temperature-independent parameters. Instead, they had to use temperature-dependent $m$ and $n$ values to describe the curing kinetics of their carbon-black-filled epoxy system. Kinetic parameters of the curing system are usually studied in systems with one or two components. However, systems relevant to practical applications are usually complicated and contain many ingredients, such as hardeners, accelerators, and fillers. Keenan ${ }^{20}$ pointed out that the use of these models to describe the true chemical reaction kinetics of a practical curing system is almost impossible. However, kinetic models can still be useful in providing empirical parameters for modeling and controlling the curing process. ${ }^{20}$ By treating $m$ and $n$ as variables, the researcher found that the curing kinetic model provides a very convenient way to describe the overall curing behavior of a commercial thermal-cure epoxy adhesive. These descriptions are useful for curing cycle modification and optimization. The same approach is used here to model the curing kinetics of our suspensions.

The rates of polymerization $\left(R_{\mathrm{p}}\right)$ of our suspensions at all curing temperatures were plotted against the percent conversion $(\alpha)$. The $R_{\mathrm{p}}$ versus $\alpha$ plots of $\mathrm{Al}_{2} \mathrm{O}_{3}$ suspension and $\mathrm{HA}$ suspension are illustrated in Fig. 10 and Fig. 11. By fitting Eq. (6) to the experimental data, the best fit parameters of $k, m$, and $n$ were determined and are listed in Table II. The $k$ parameter for both suspensions followed an Arrhenius relation with the inverse of curing temperature. The $m$ and $n$ for both suspensions followed a linear relation with curing temperature. The same type of linear relation between curing temperature and the $m$ and $n$ values also was observed by Dutta and Ryan. ${ }^{17}$ From these results, empirical kinetic equations for $\mathrm{Al}_{2} \mathrm{O}_{3}$ and $\mathrm{HA}$ suspensions were developed as follows:

$$
\begin{aligned}
& R_{\mathrm{pA}_{2} \mathrm{O}_{3} \text { Slip }}=1.05 \times 10^{12} \\
& \quad \exp (-94625 / R T)(\alpha)^{0.0085 T-2.578}(1-\alpha)^{0.0243 T-7.3189} \\
& R_{\mathrm{p}_{\mathrm{HA} \mathrm{slip}}}=2.7 \times 10^{8} \\
& \quad \exp (-74827 / R T)(\alpha)^{-0.0035 T-1.4085}(1-\alpha)^{0.005 T-1.115}
\end{aligned}
$$

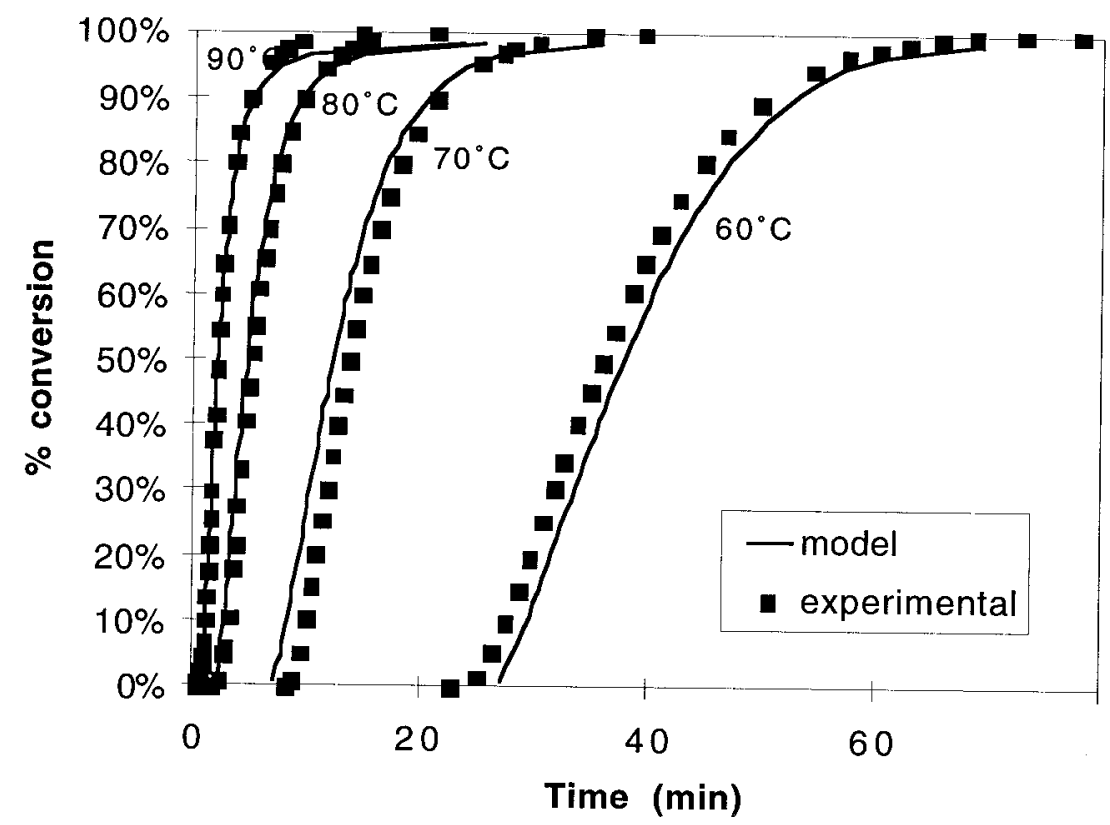

Fig. 14. Model and experimental data of percent conversion vs time for $\mathrm{Al}_{2} \mathrm{O}_{3} / \mathrm{PNPGDA} / \mathrm{IBA}$ cured at at $60^{\circ}, 70^{\circ}, 80^{\circ}$, and $90^{\circ} \mathrm{C}$. 


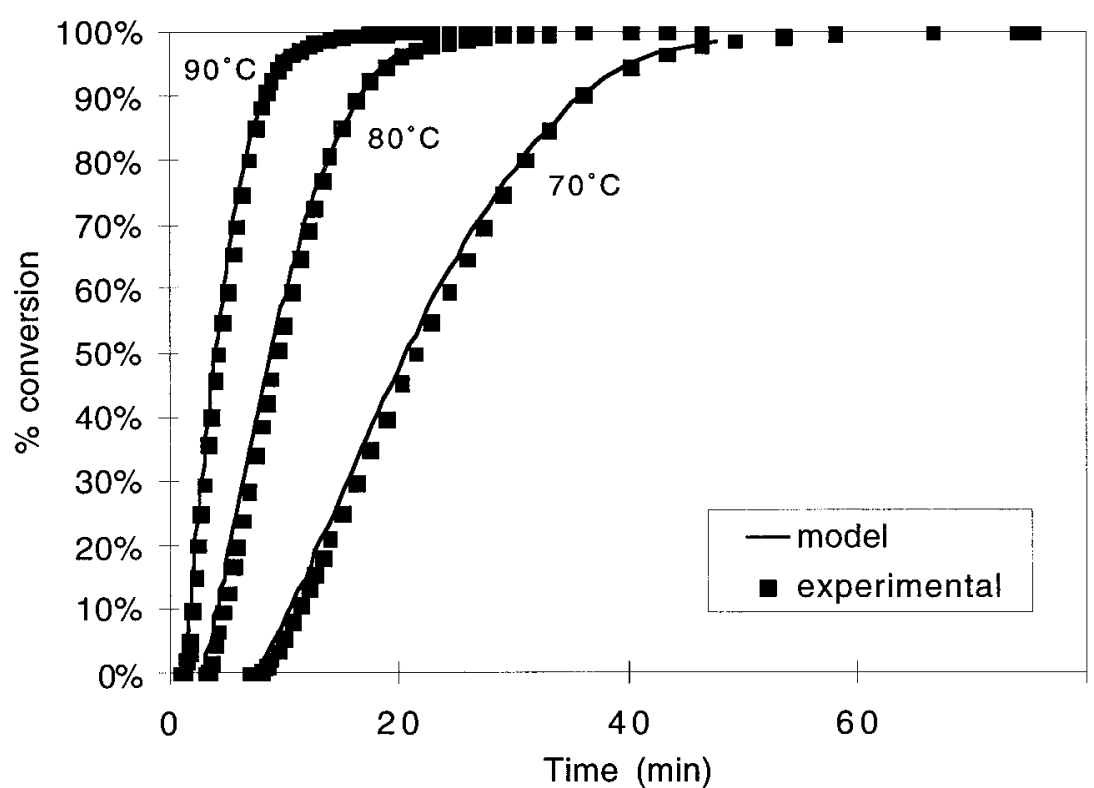

Fig. 15. Model and experimental data of percent conversion vs time for HA/PNPGDA/IBA cured at $70^{\circ}, 80^{\circ}$, and $90^{\circ} \mathrm{C}$.

where $R_{\mathrm{p}}$ is the rate of polymerization, $R$ the gas constant in $\mathrm{J} / \mathrm{mol}$, and $T$ the temperature in degrees Kelvin. With Eqs. (7) and (8), the rate of polymerization for the $\mathrm{Al}_{2} \mathrm{O}_{3}$ suspension and $\mathrm{HA}$ suspension is calculated with $\alpha$ from $0 \%$ to $100 \%$. The calculated results of $\mathrm{Al}_{2} \mathrm{O}_{3}$ and $\mathrm{HA}$ suspensions are illustrated in Fig. 12 and Fig. 13 along with the experimental data. The ability of the model to reproduce the curing curve is confirmed. These results show that the autocatalytic kinetic model with $m$ and $n$ values as variables is useful in providing phenomenological descriptions for the curing kinetics of our complicated ceramic suspensions that contain $68-80$ wt $\%$ of ceramics, dispersants, initiators, and two different monomers.

The usefulness of this model could be further demonstrated in modeling the percent conversion of the suspension throughout the curing process. The initiation time of the $\mathrm{Al}_{2} \mathrm{O}_{3}$ and $\mathrm{HA}$ suspensions was first plotted against the inverse of the curing temperature. A linear relation was again found between the logarithm of initiation time and the inverse of the curing temperature. The initiation time of the $\mathrm{Al}_{2} \mathrm{O}_{3}$ and $\mathrm{HA}$ slips was modeled as:

$$
\begin{aligned}
& t_{\text {ini }\left(\mathrm{Al}_{2} \mathrm{O}_{3}\right)}=1.2 \times 10^{-17} \exp (15435 / T) \\
& t_{\text {ini( }(\mathrm{HA})}=3.0 \times 10^{-13} \exp (12018 / T)
\end{aligned}
$$

where $T$ is the curing temperature in degrees Kelvin. Combining Eqs. (7), (8), and (9), the percent conversion versus time of the $\mathrm{Al}_{2} \mathrm{O}_{3}$ and $\mathrm{HA}$ suspensions are calculated and shown in Fig. 14 and Fig. 15. The model reproduces the profile of the experimental data. The results show that the percent conversion versus time at different curing temperatures can be modeled, and the time to reach certain percent conversion can be estimated.

\section{Conclusions}

The curing kinetics of two highly filled ceramic suspensions and the acrylate premix were studied using DSC. The activation energy of the suspensions was calculated from the peak reaction rate in the isothermal cure. The activation energy of the premix was obtained from the dynamic DSC scan. Reduction in the activation energy of the suspension indicated the catalytic effect of ceramic fillers on the polymerization reaction of the acrylate premix. An autocatalytic kinetic model was fitted to the curing kinetic data. The results showed that the kinetic model can give a satisfactory description of the curing process of these systems.

\section{References}

${ }^{1}$ K. Venkataswamy, R. Waack, B. Novich, and J. Halloran, "Forming Whisker Reinforced Sintered Ceramics with Polymerizable Binder Precursors," U. S. Pat. No. 4978 643, December 18, 1990.

${ }^{2}$ M. A. Janney, "Method for Molding Ceramic Powders," U. S. Pat. No. 4894 194, January 16, 1990.

${ }^{3}$ A. C. Young, O. O. Omatete, M. A. Janney, and P. A. Menchhofer, "Gelcasting of Alumina," J. Am. Ceram. Soc., 74, 612-18 (1991).

${ }^{4}$ O. O. Omatete, M. A. Janney, and R. A. Strehlow, "Gelcasting - A New Ceramic Forming Process," Am. Ceram. Soc. Bull., 70, 1641-48 (1991).

${ }^{5}$ R. B. Prime, "Thermosets"; pp. 435-563 in Thermal Characterization of Polymeric Materials. Edited by E. A. Turi. Academic Press, New York, 1981.

${ }^{6}$ A. Ruys, M. Wei, C. Sorrell, M. Dickson, A. Brandwood, and B. Milthorpe, "Sintering Effects on the Strength of Hydroxyapatite," J. Mater. Sci.: Mater. Med., 16, 409-15 (1995).

${ }^{7}$ T.-M. G. Chu and J. W. Halloran, "High Temperature Flow Behavior of Ceramic Suspensions," J. Am. Ceram. Soc., 83 [9] 2189-95 (2000).

${ }^{8}$ T. -M. G. Chu, J. W. Halloran, S. J. Hollister, and S. E. Feinberg, "Hydroxyapatite Implants with Designed Internal Architecture," J. Mater. Sci.: Mater. Med., in press.

${ }^{9}$ G. Odian, "Radial Chain Polymerization"; pp. 198-334 in Principles of Polymerization. Edited by G. Odian. Wiley, New York, 1991.

${ }^{10}$ K.-W. Lem and C. D. Han, "Chemorheology of Thermosetting Resins. II. Effect of Particulates on the Chemorheology and Curing Kinetics of Unsaturated Polyester Resin," J. Appl. Polym. Sci., 28, 3185-206 (1983).

${ }^{11}$ W. K. Busfield, "Heats and Entropies of Polymerization, Ceiling Temperatures, Equilibrium Monomer Concentrations; and Polymerizability of Heterocylic Compounds"; pp. 298 in Polymer Handbook. Edited by J. Brandrup and E. H. Immergut. Wiley, New York, 1989.

${ }^{12}$ A. A. Duswalt, "The Practice of Obtaining Kinetic Data by Differential Scanning Calorimetry," Thermochim. Acta, 8, 57-68 (1974).

${ }^{13}$ Y. Grohens, F. Touyeras, B. George, and J. Vebrel, "Effects of Inhibitor and Cure Promoter on Unsaturated Polyester Cure and Mechanical Properties," J. Mater. Sci. Lett., 14, 1460-62 (1995).

${ }^{14}$ E. M. Pearce, C. E. Wright, and B. K. Bordoloi, "Free-Radical Copolymerization"; pp. 27-35 in Laboratory Experiments in Polymer Synthesis and Characterization. Edited by E. M. Pearce, C. E. Wright, and B. K. Bordoloi. Pennsylvania State University, University Park, PA, 1982.

${ }^{15}$ A. Thakur, A. K. Banthia, and B. R. Maiti, "Studies on Curing Kinetics of Multifunctional Acrylates by Infra-red Spectroscopy," Macromolecular Reports, A32 [Suppl. 1, 2] 189-96 (1995)

${ }^{16}$ J.-Y. Lee, M.-J. Shim, and S.-W. Kim, "Autocatalytic Cure Kinetics of Natural Zeolite Filled Epoxy Composites," Mater. Chem. Phys., 48, 36-40 (1997).

${ }^{17}$ A. Dutta and M. Ryan, "Effect of Fillers on Kinetics of Epoxy Cure," J. Appl. Polym. Sci., 24, 635-49 (1979).

${ }^{18}$ M. R. Kamal, "Kinetics and Thermal Characterization of Thermoset Cure," Polym. Eng. Sci., 13, 59-64 (1973).

${ }^{19}$ M. R. Kamal, S. Sourour, and M. Ryan, "Integrated Therm-rheological Analysis of the Cure of Thermosets"; pp. 187-91 in Proceedings of the 31st Annual Technical Conference (Quebec, Canada, 1973). Edited by Society of Plastic Engineers, 1973.

${ }^{20}$ M. Keenan, "Autocatalytic Cure Kinetics from DSC Measurements: Zero Initial Cure Rate,” J. Appl. Polym. Sci., 33, 1725-34 (1987). 